\title{
Discovery of 7,9-Disulfatetrahydroberberine as Novel Lipid-lowering Agents
}

\author{
Dong-Dong $\mathrm{Li}^{1,2, \#,}$ Pan $\mathrm{Yu}^{1,2, \#}$, Zhen-Zhong Wang ${ }^{3}$, Wei Xiao ${ }^{3,{ }^{*}}$, Xin-Hu Zhou ${ }^{4, *}$, \\ Lin-Guo Zhao ${ }^{1,2, *}$
}

${ }^{1}$ Jiangsu Co-Innovation Center of Efficient Processing and Utilization of Forest Resources, Nanjing Forestry University, Nanjing 210037, People's Republic of China

${ }^{2}$ College of Chemical Engineering, Nanjing Forestry University, 159 Long Pan Road, Nanjing 210037, China

${ }^{3}$ Jiangsu Kanion Pharmaceutical Co., Ltd., 58 Haichang South Road, Lianyungang 222001, Jiangsu Province, China

${ }^{4}$ Jiangsu Yanghe Distillery Co. Ltd., Suqian 223800, Jiangsu Province, China

\# These authors equally contributed to this work. 
${ }^{1} \mathrm{H}-\mathrm{NMR}$ and ${ }^{13} \mathrm{C}-\mathrm{NMR}$ of some representative compounds

Figure S1 ${ }^{1} \mathrm{H}$ NMR Spectrum of Compound 2

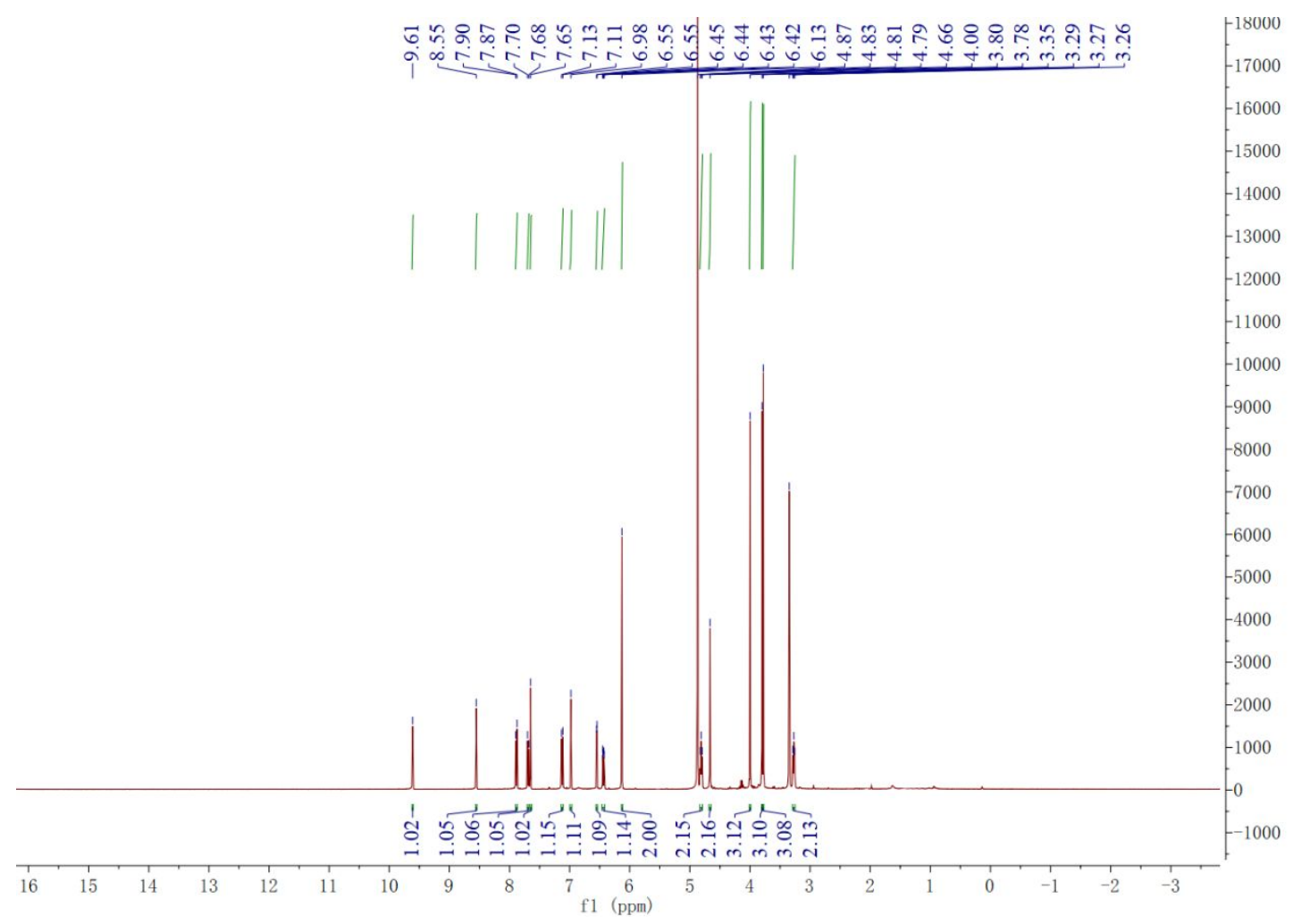

Figure S2 ${ }^{13} \mathrm{C}$ NMR Spectrum of Compound $\mathbf{2}$ 


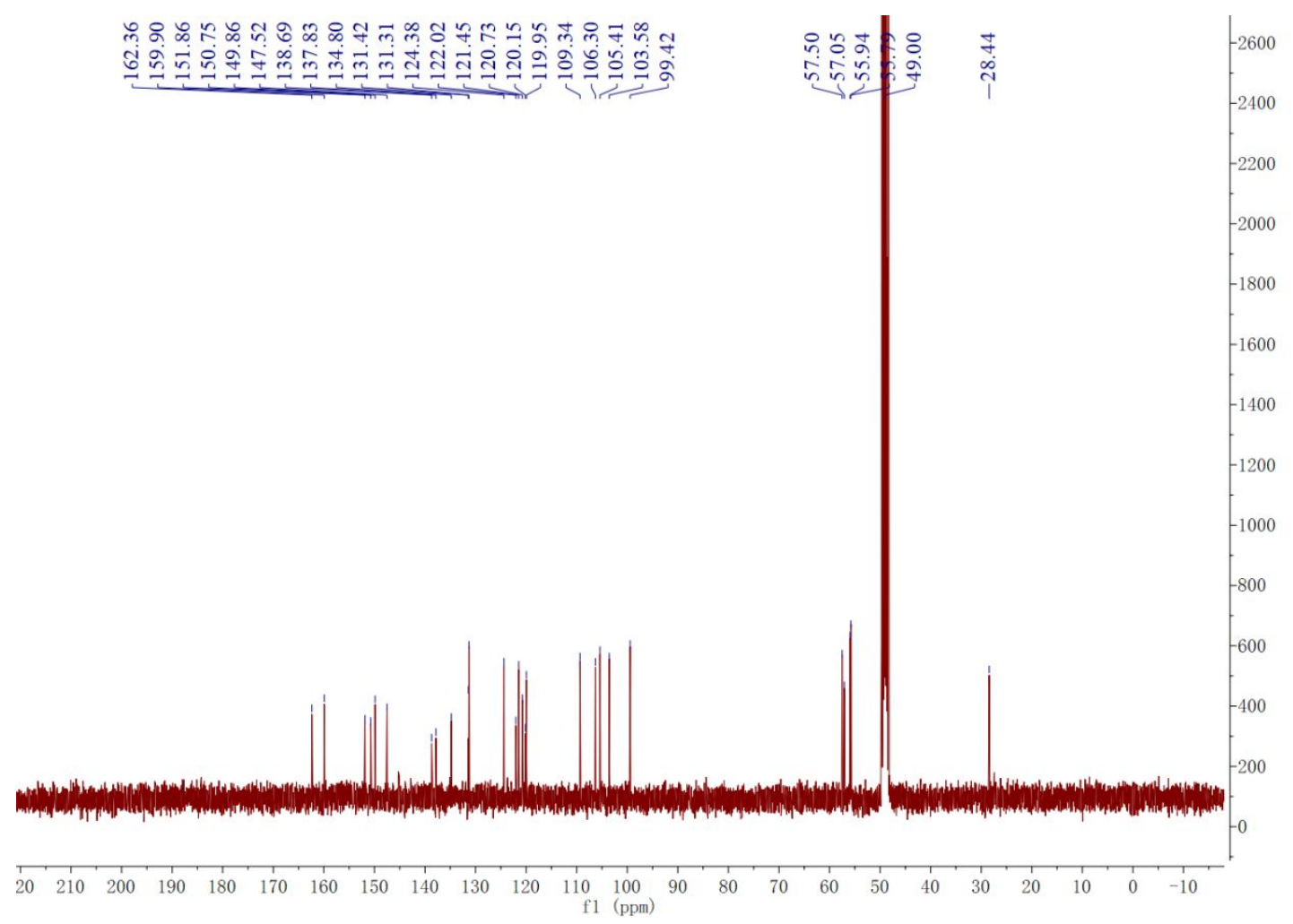

Figure S3 ${ }^{1} \mathrm{H}$ NMR Spectrum of Compound $\mathbf{3}$

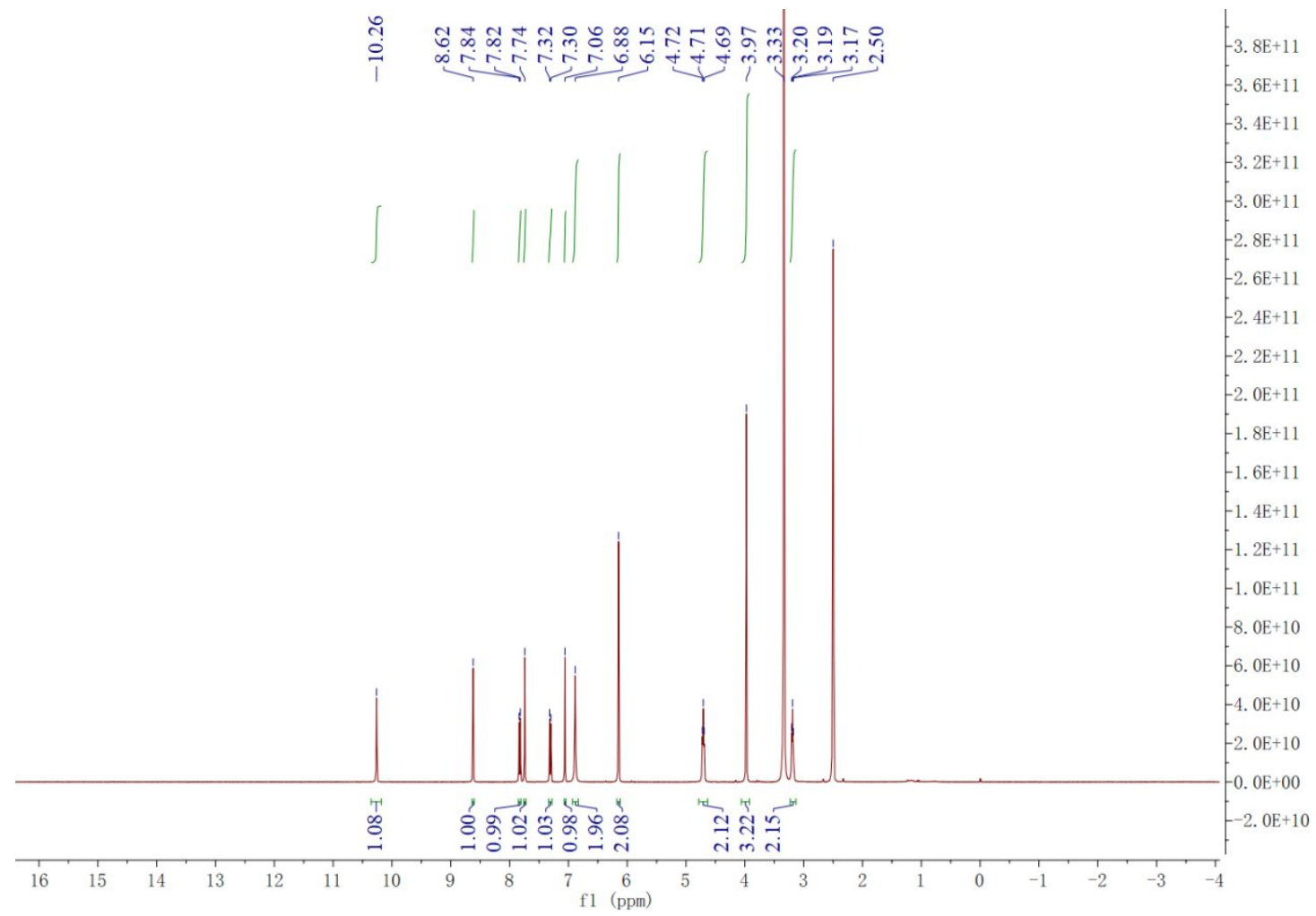


Figure S4 ${ }^{1} \mathrm{H}$ NMR Spectrum of Compound 4

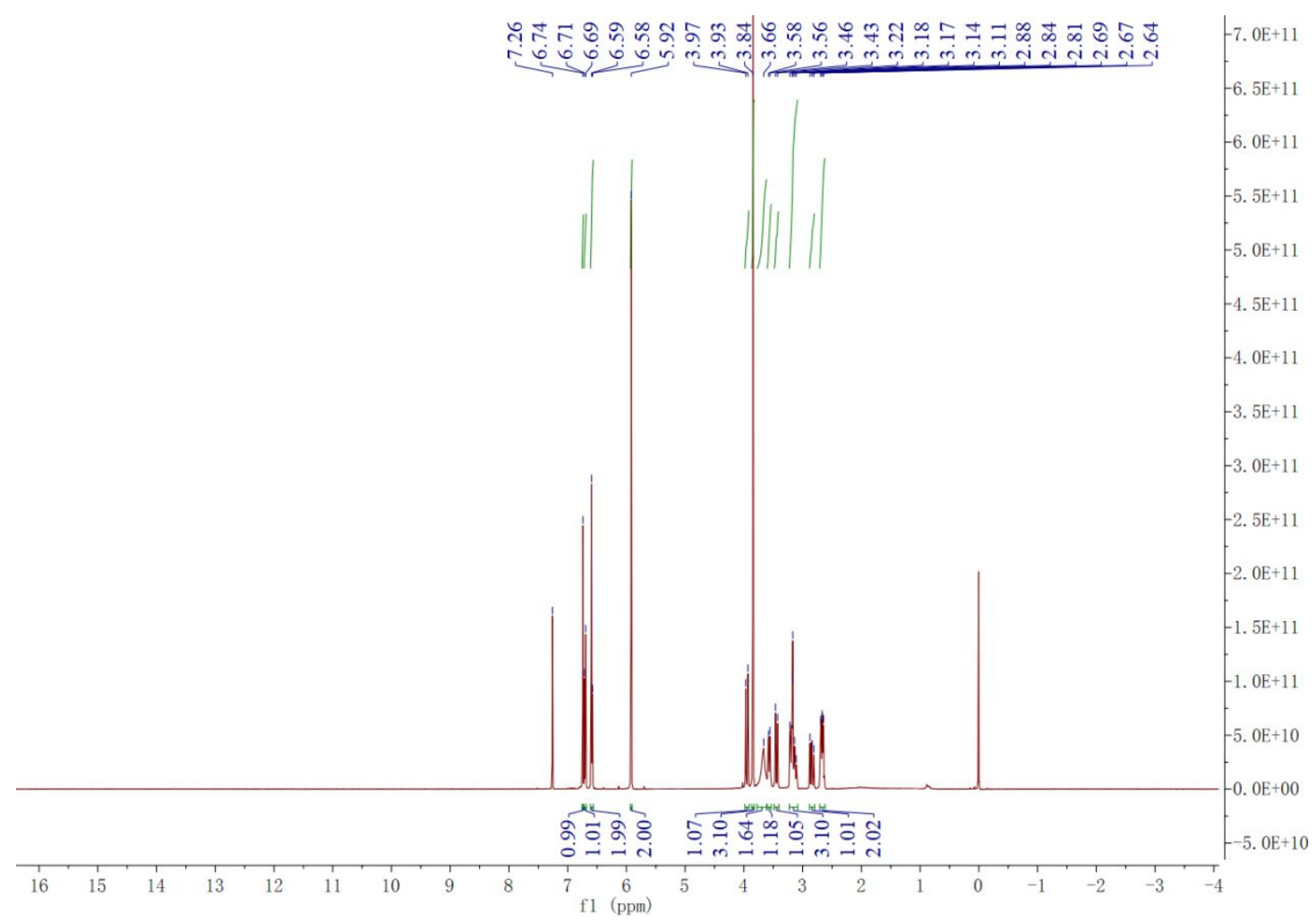

Figure S5 ${ }^{1} \mathrm{H}$ NMR Spectrum of Compound 5a 


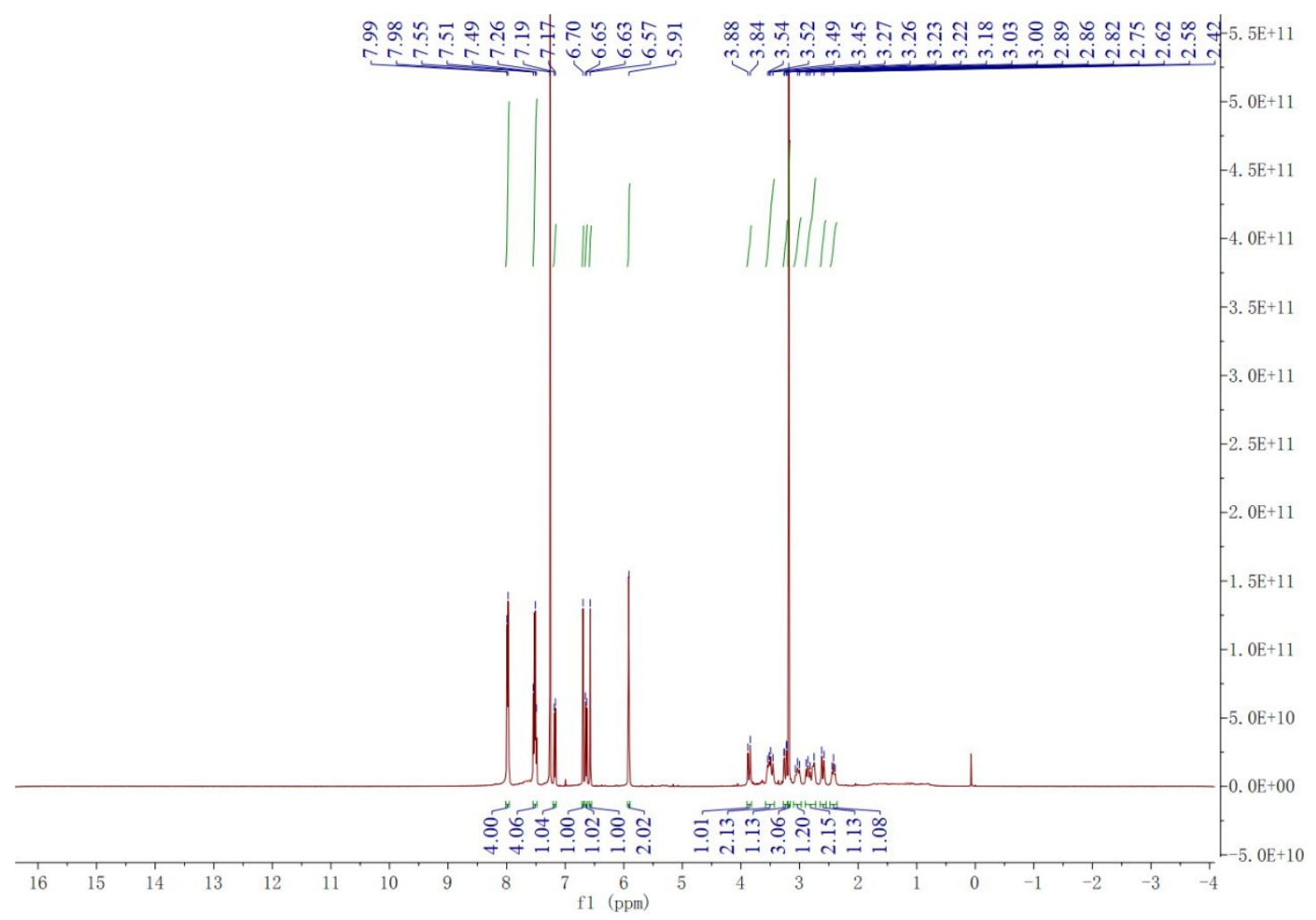

Figure S6 ${ }^{1} \mathrm{H}$ NMR Spectrum of Compound $\mathbf{5 b}$

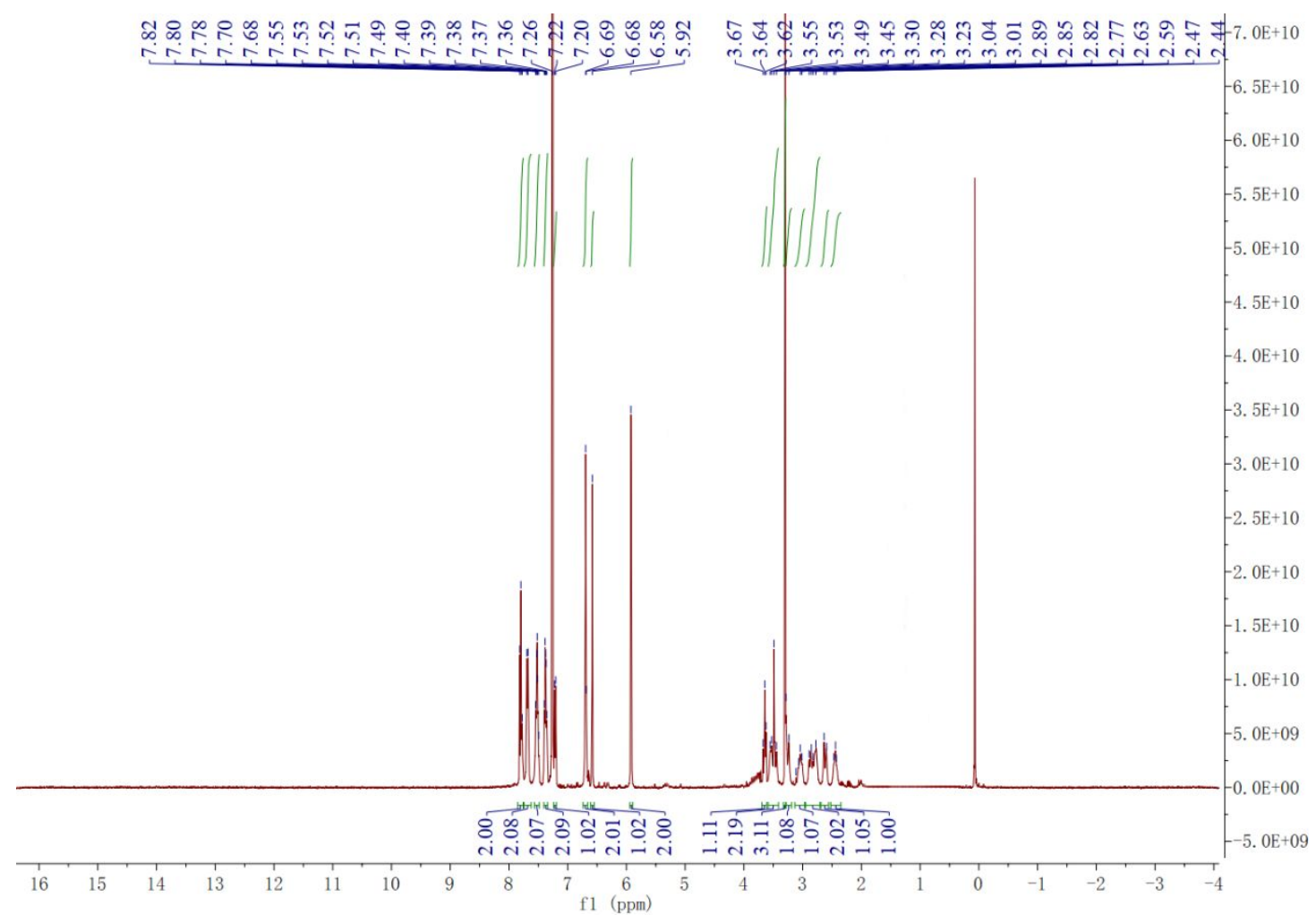


Figure S7 ${ }^{1} \mathrm{H}$ NMR Spectrum of Compound $\mathbf{5 c}$

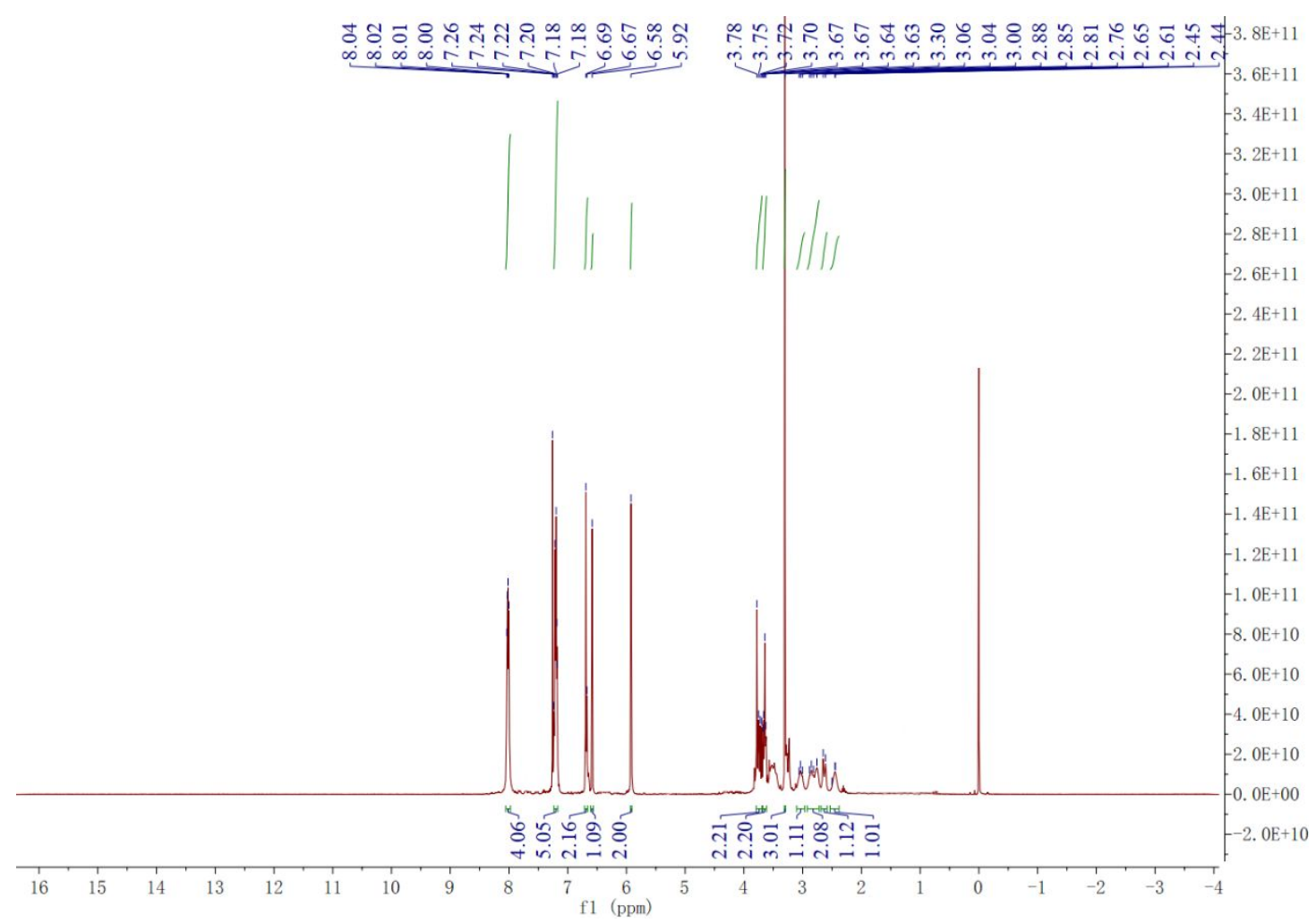

Figure S8 ${ }^{1} \mathrm{H}$ NMR Spectrum of Compound $\mathbf{5 d}$ 


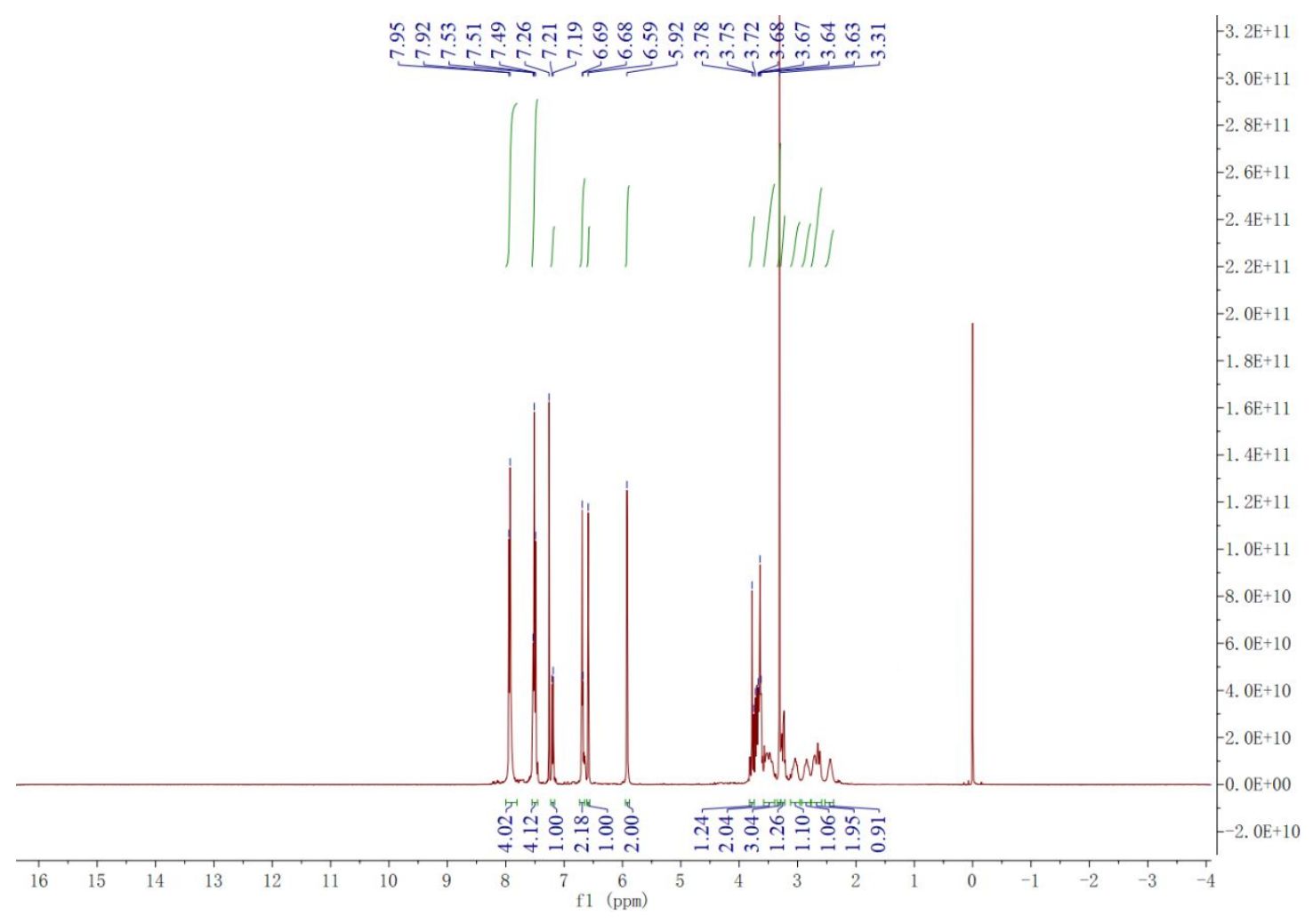

Figure S9 ${ }^{1} \mathrm{H}$ NMR Spectrum of Compound $5 \mathbf{e}$ 


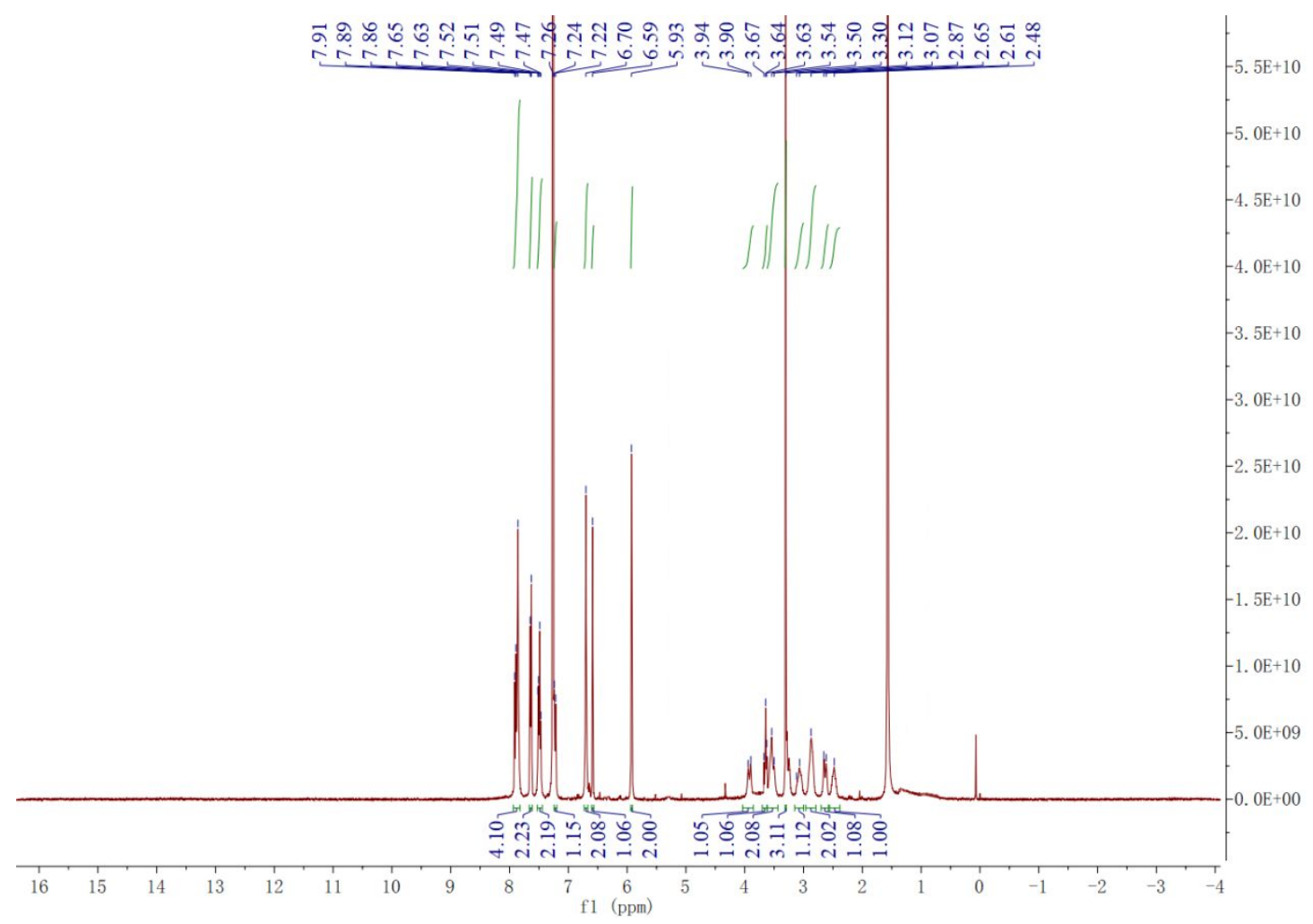

Figure S10 ${ }^{1} \mathrm{H}$ NMR Spectrum of Compound $\mathbf{5 f}$

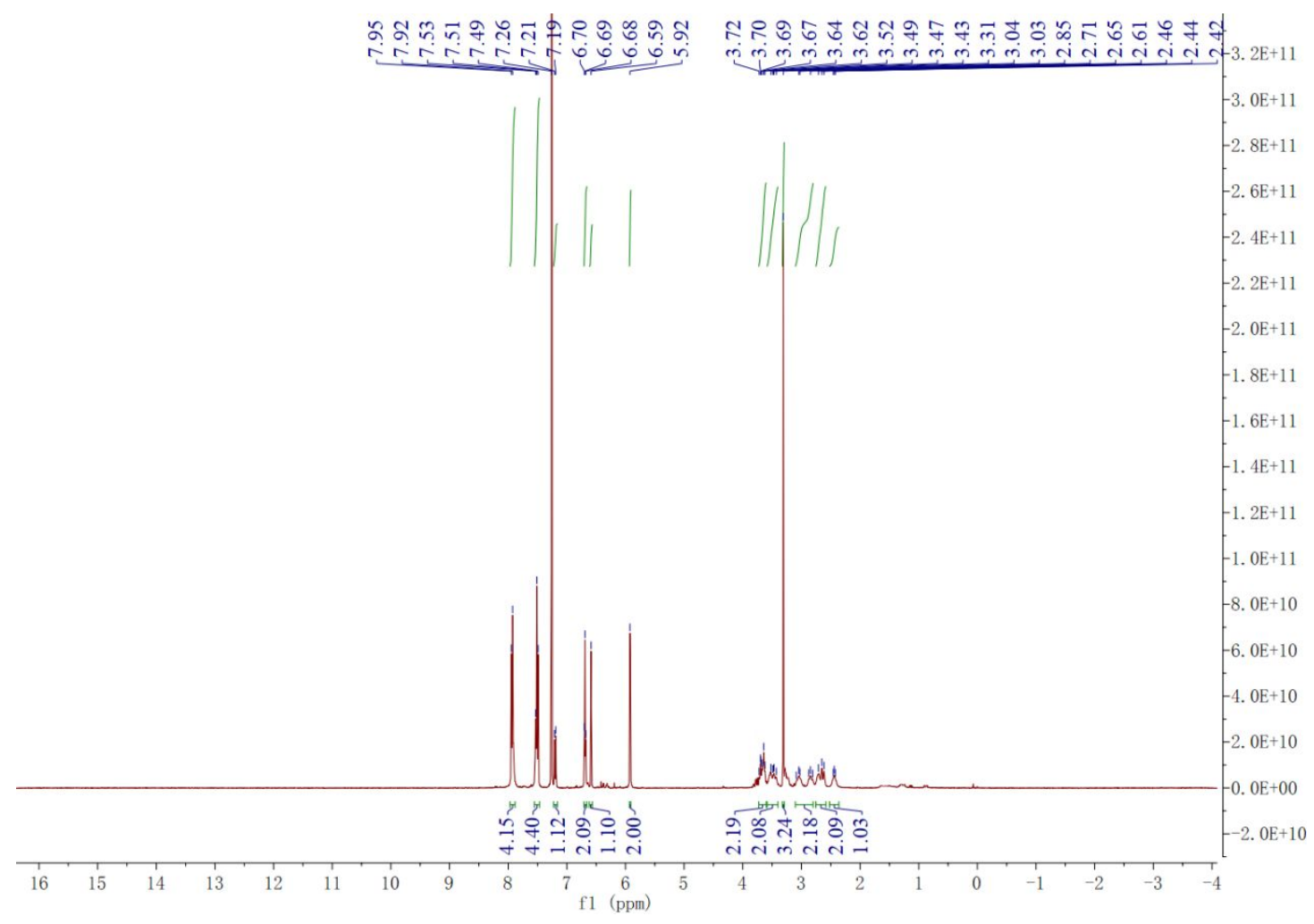


Figure S11 ${ }^{1} \mathrm{H}$ NMR Spectrum of Compound $\mathbf{5 g}$

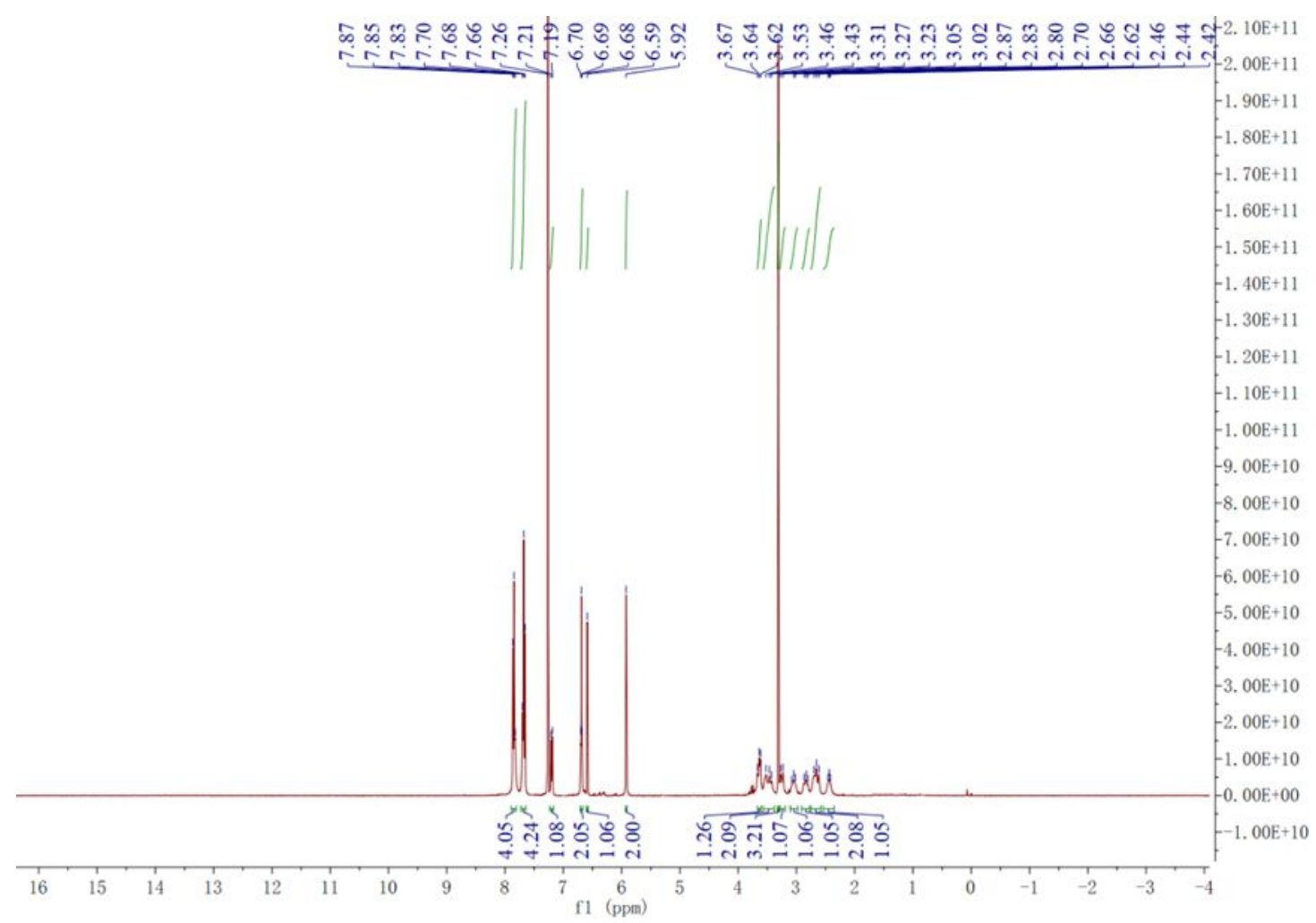

Figure S12 ${ }^{1} \mathrm{H}$ NMR Spectrum of Compound $\mathbf{5 h}$ 


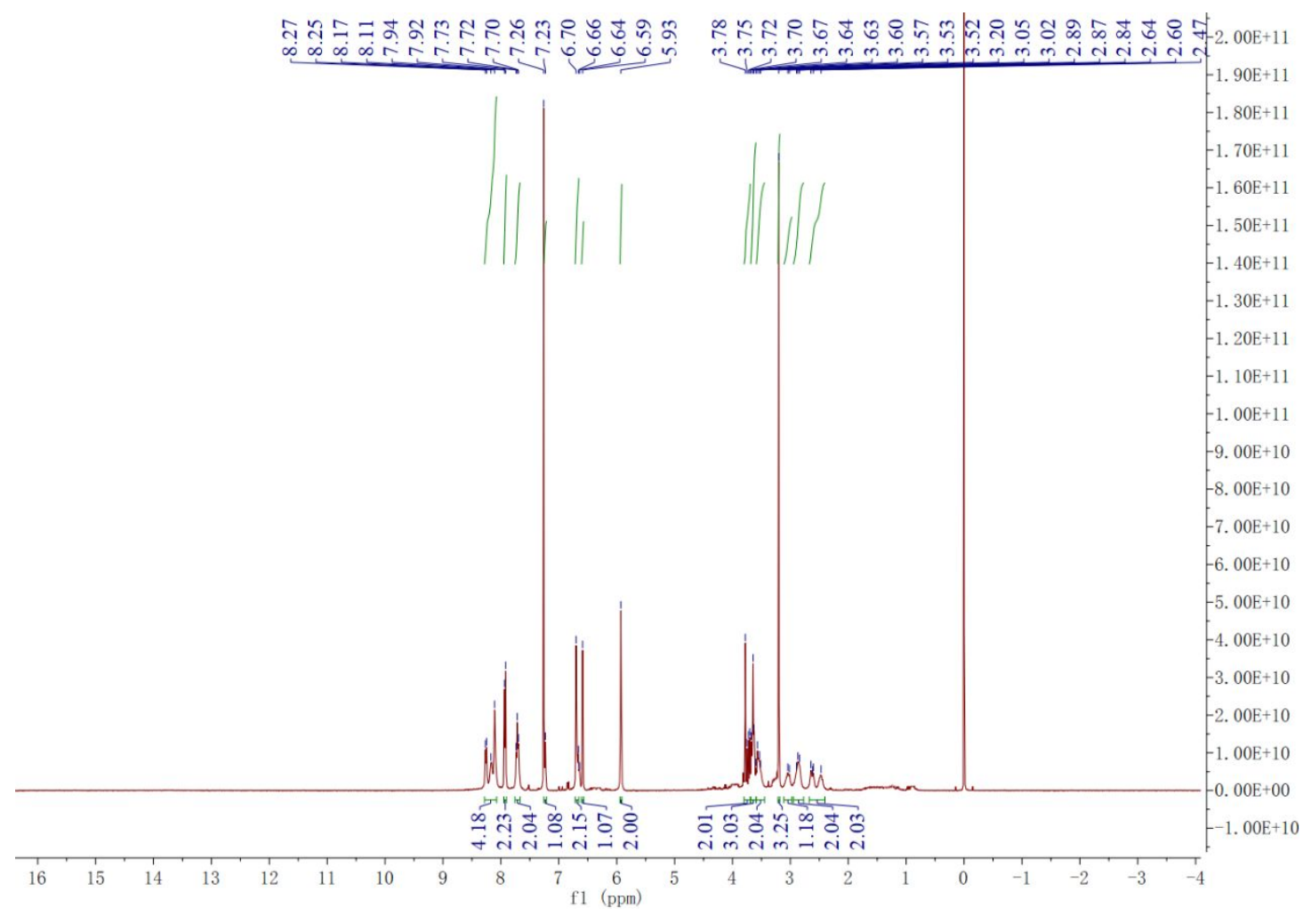

Figure S13 ${ }^{1} \mathrm{H}$ NMR Spectrum of Compound $\mathbf{5 i}$ 


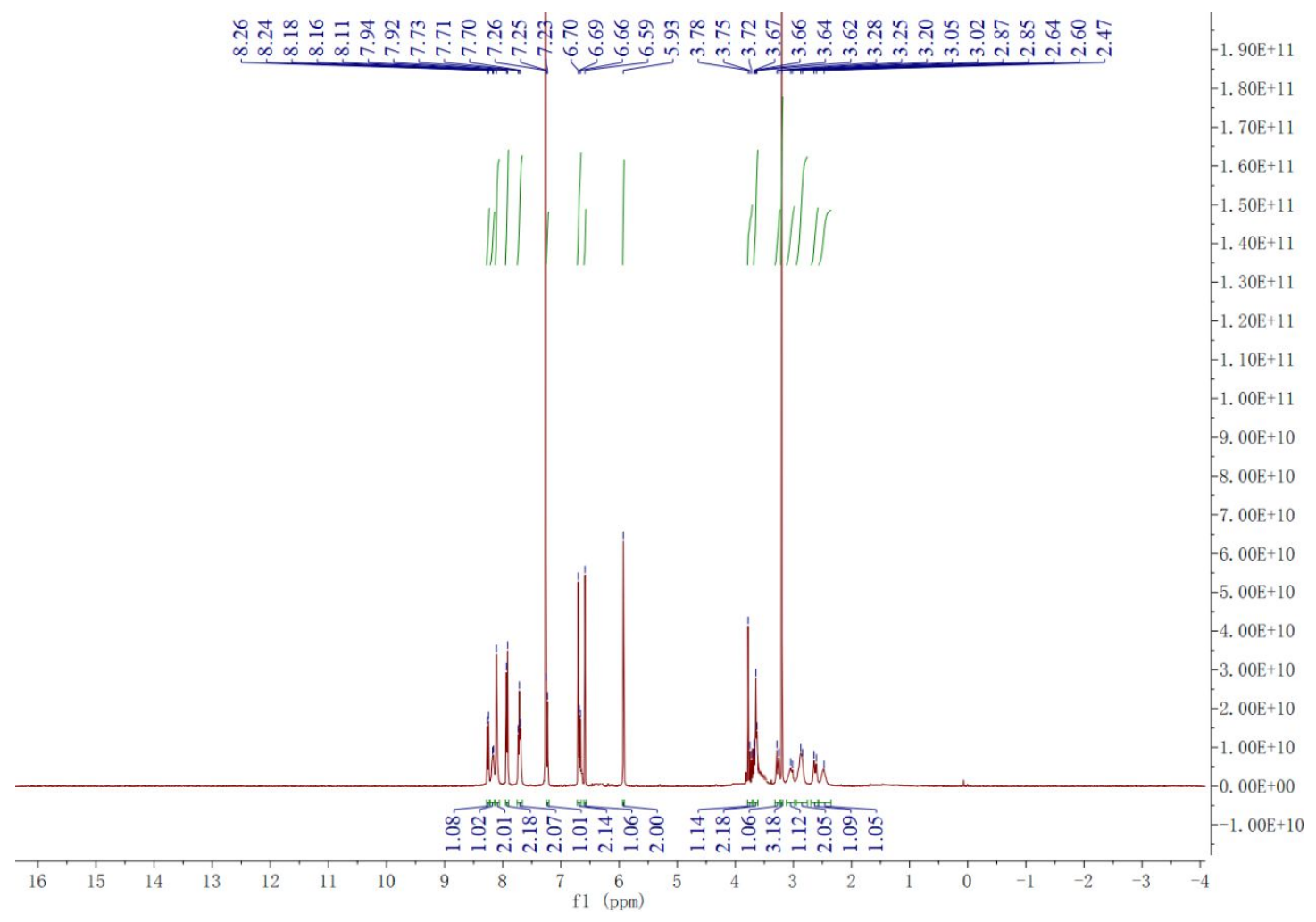

Figure S14 ${ }^{1} \mathrm{H}$ NMR Spectrum of Compound $\mathbf{5 j}$

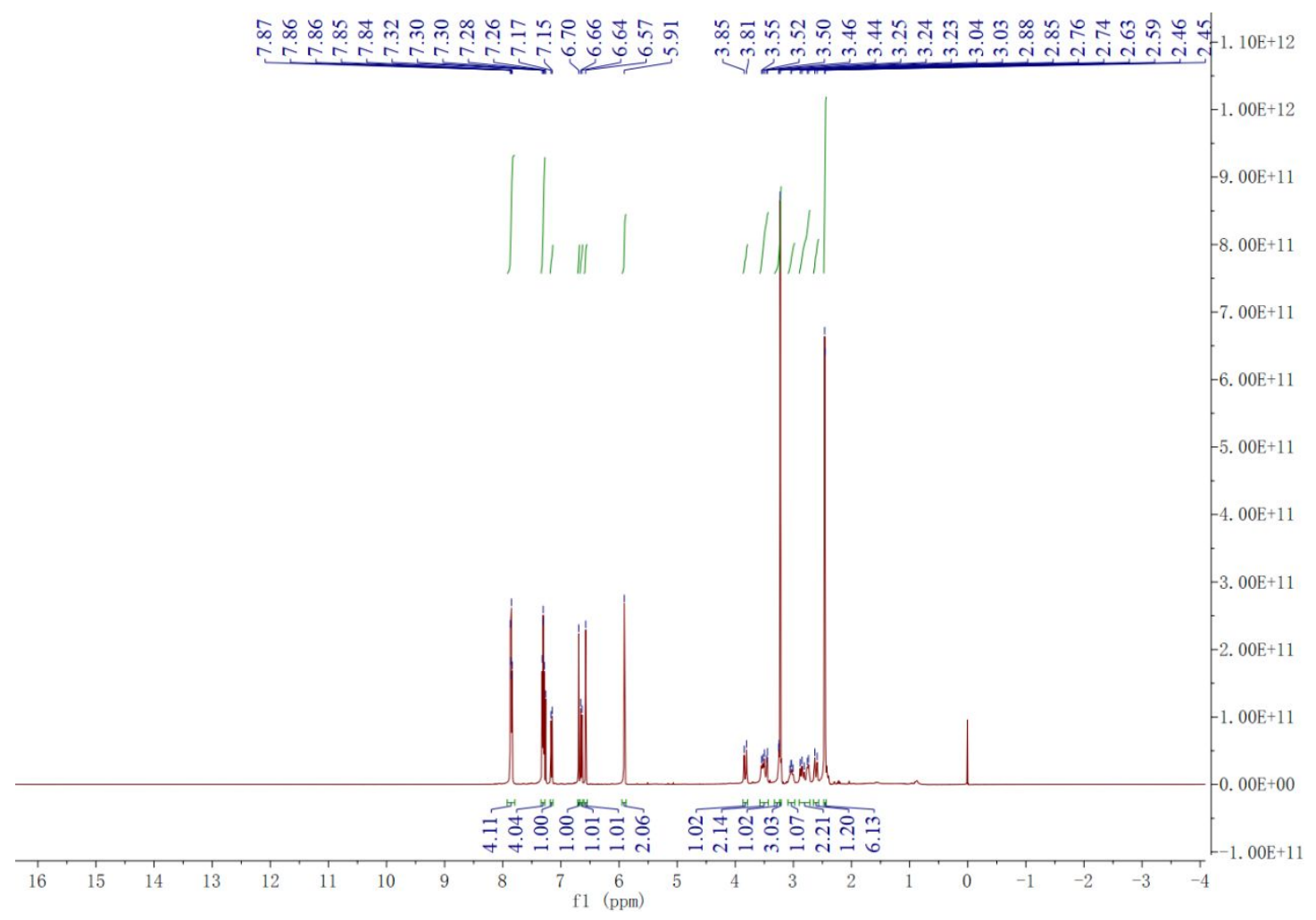


Figure S15 ${ }^{1} \mathrm{H}$ NMR Spectrum of Compound $5 \mathbf{k}$

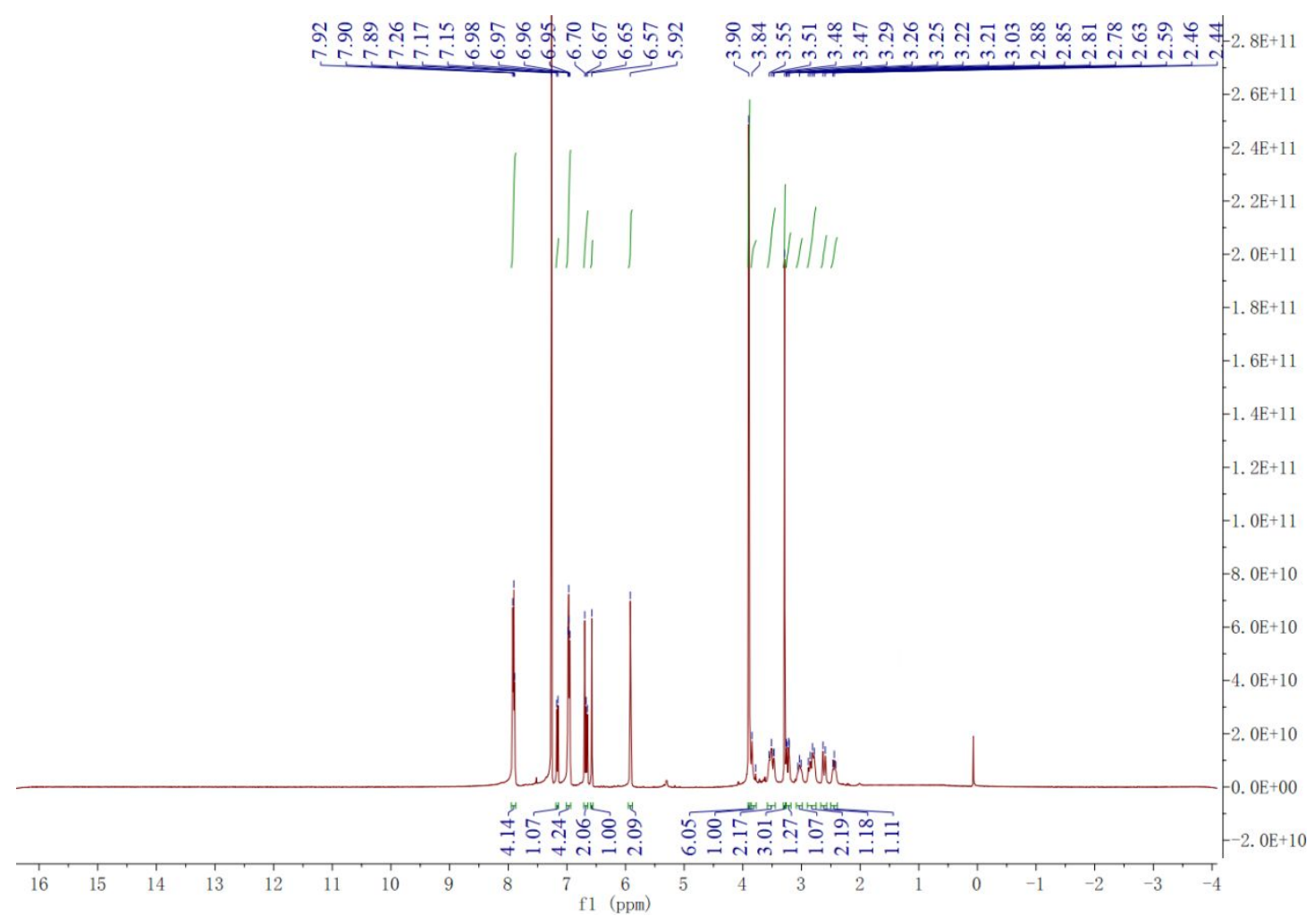

Figure S16 ${ }^{1} \mathrm{H}$ NMR Spectrum of Compound 5n 


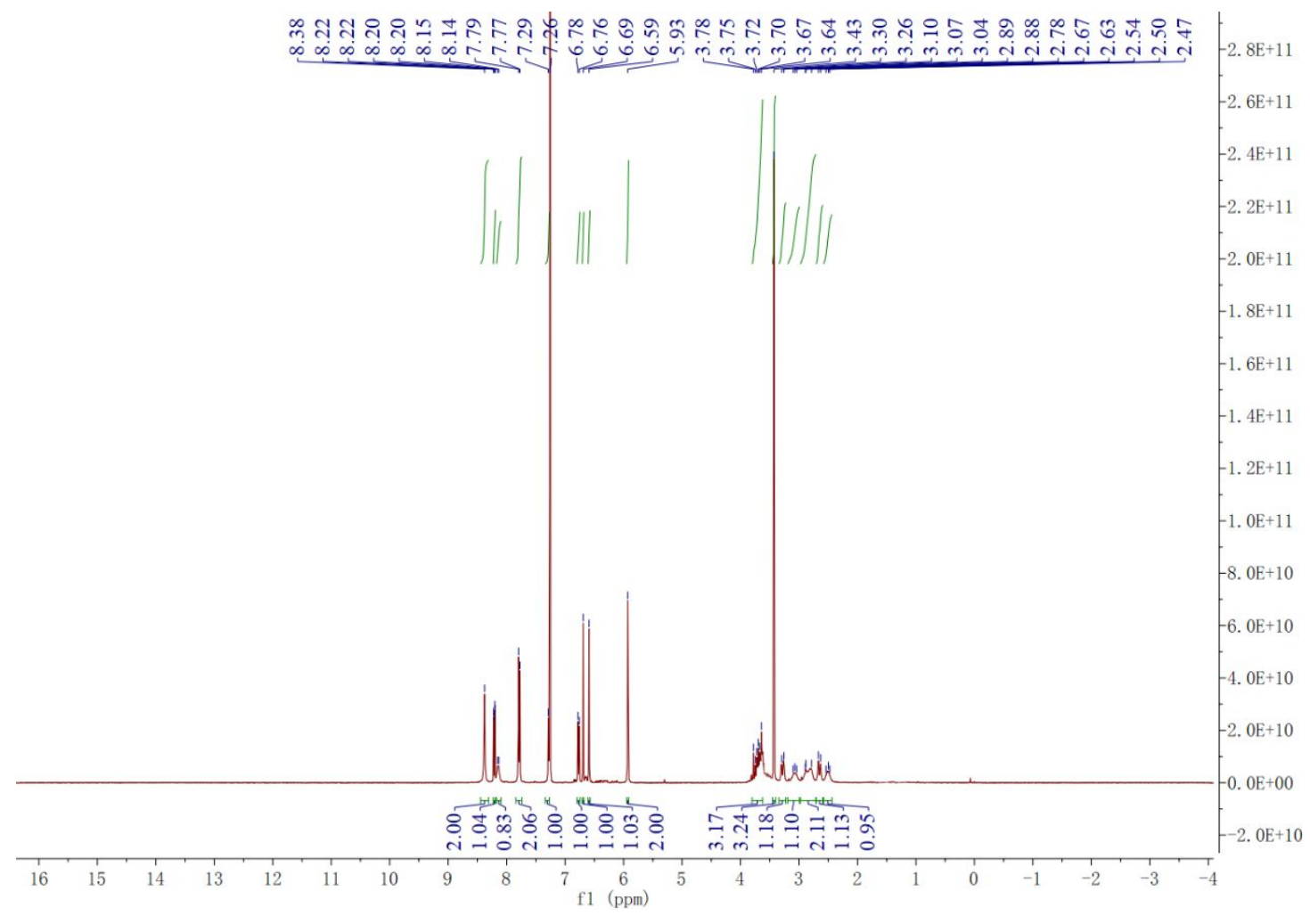

Figure S17 ${ }^{1} \mathrm{H}$ NMR Spectrum of Compound $\mathbf{8 a}$ 


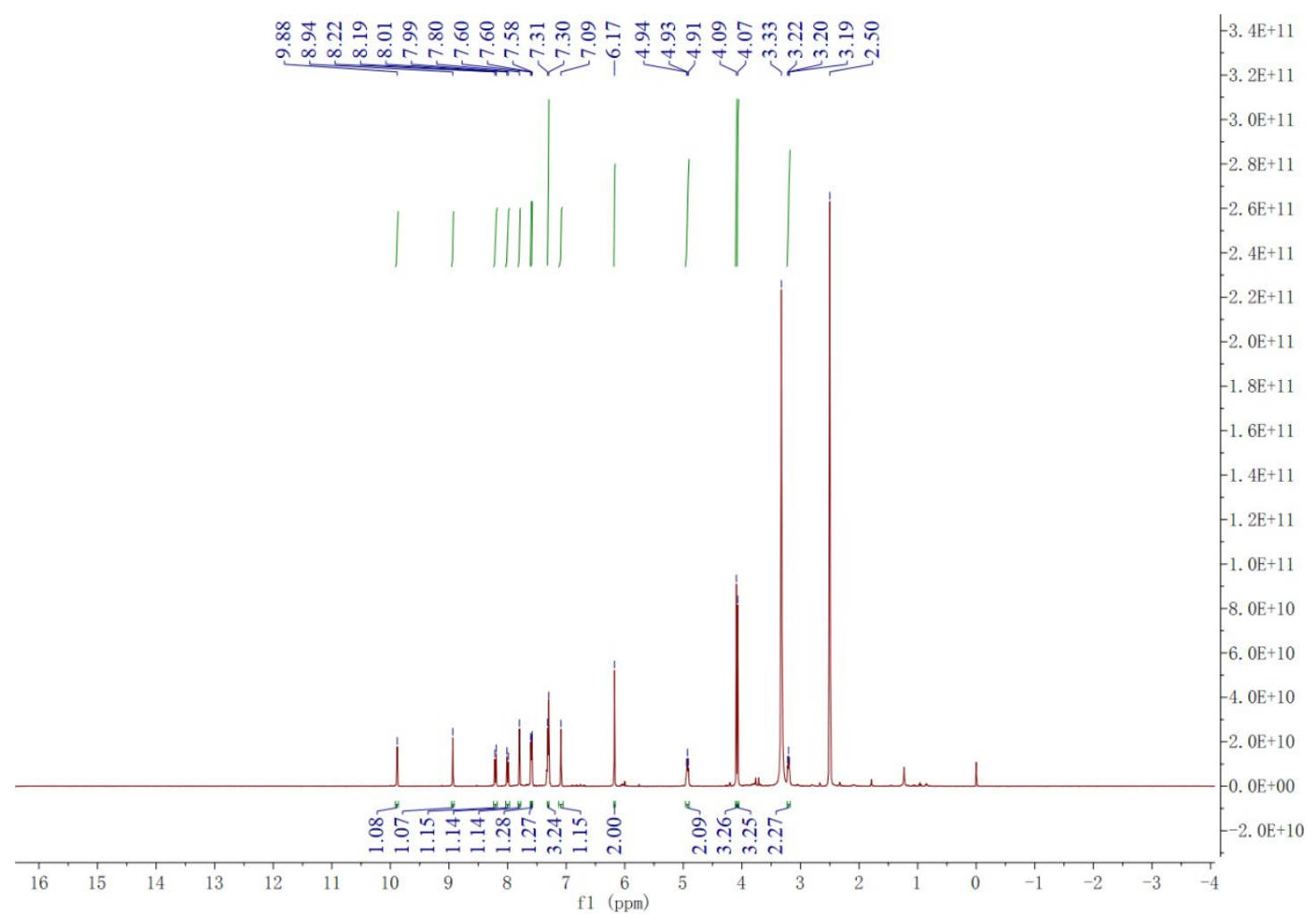

Figure S18 ${ }^{1} \mathrm{H}$ NMR Spectrum of Compound $\mathbf{8 b}$

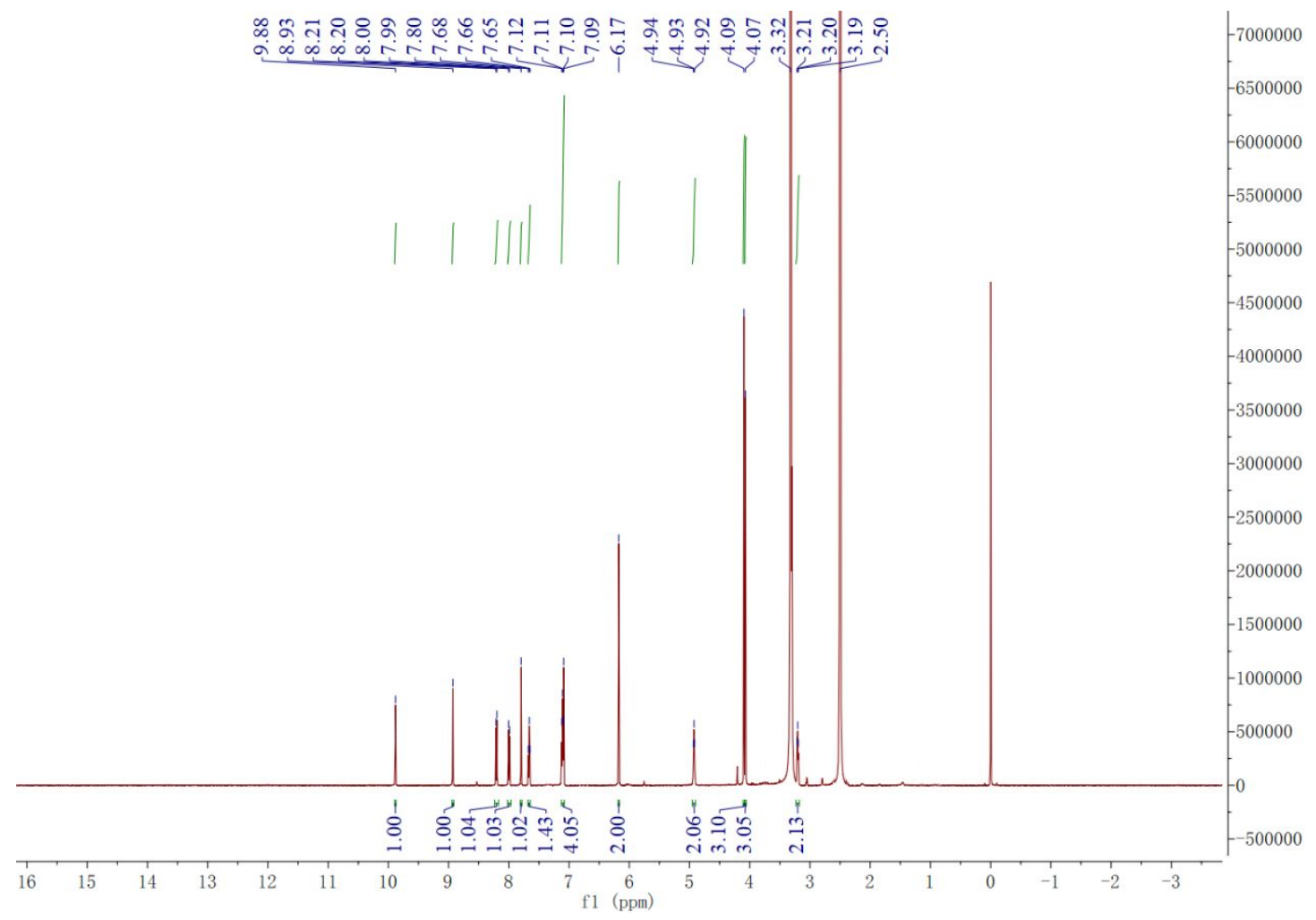


Figure S19 ${ }^{1} \mathrm{H}$ NMR Spectrum of Compound $8 \mathrm{e}$

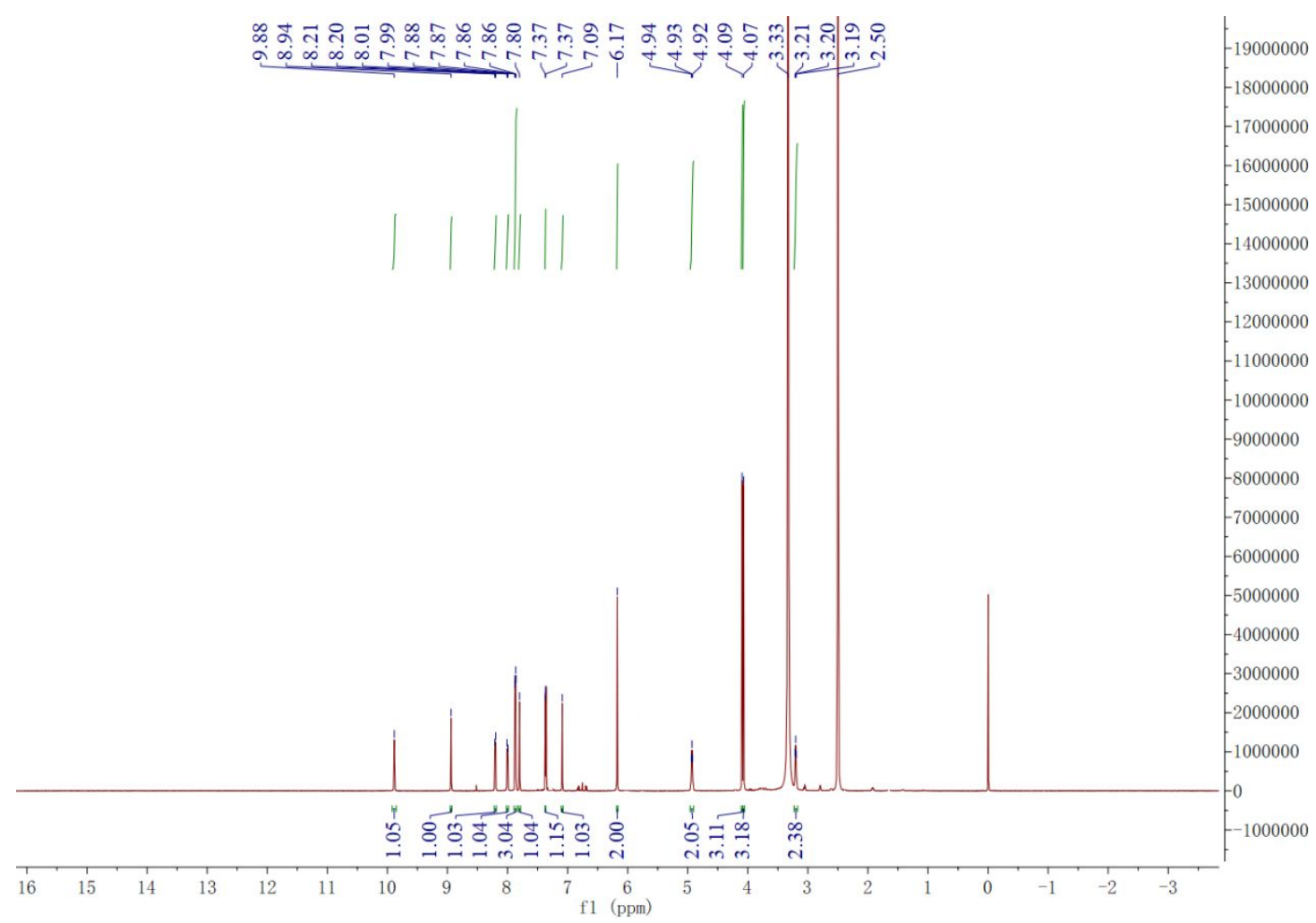

Figure S20 ${ }^{1} \mathrm{H}$ NMR Spectrum of Compound $\mathbf{8 h}$ 


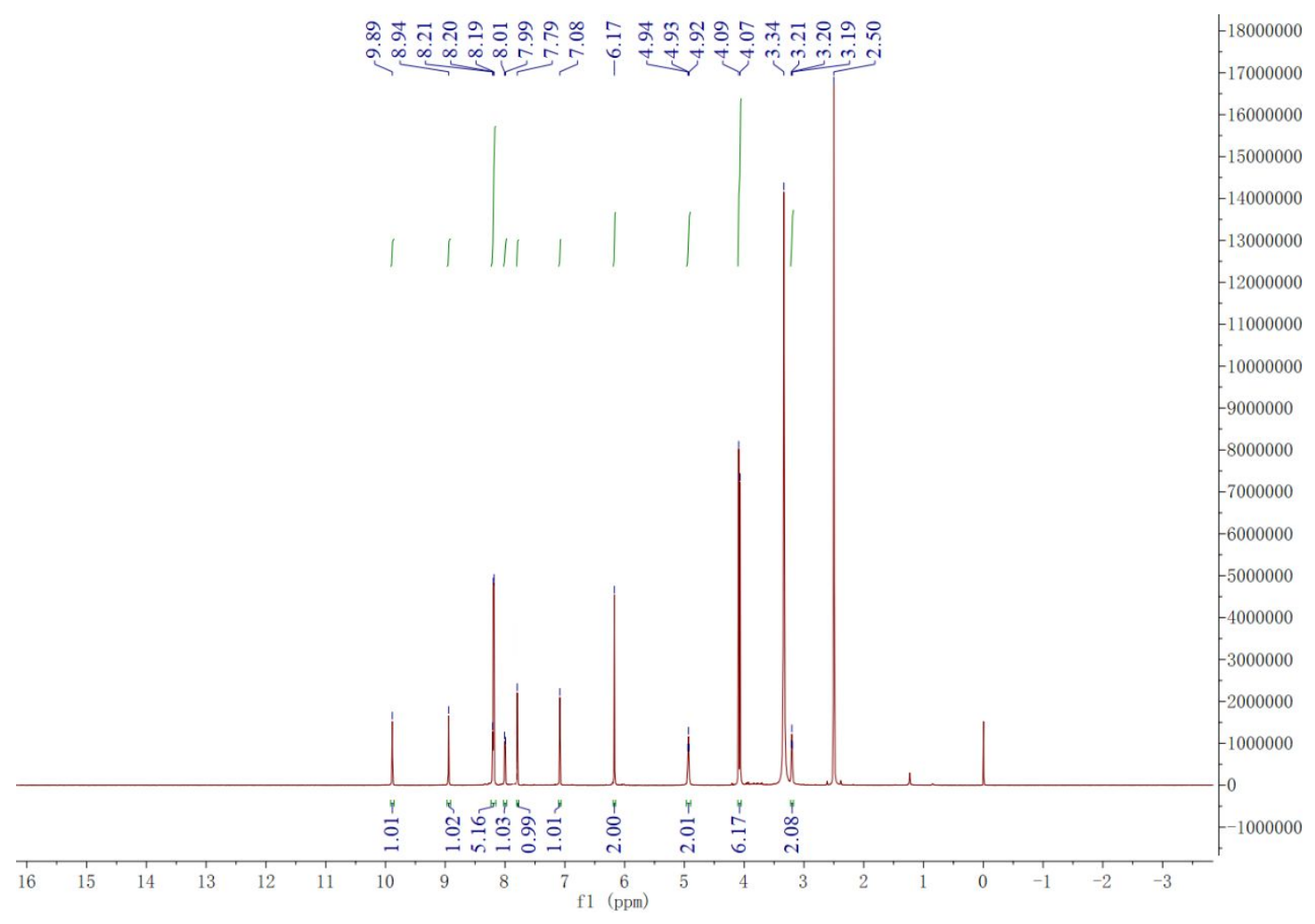

Figure S21 ${ }^{1} \mathrm{H}$ NMR Spectrum of Compound $\mathbf{8 j}$ 


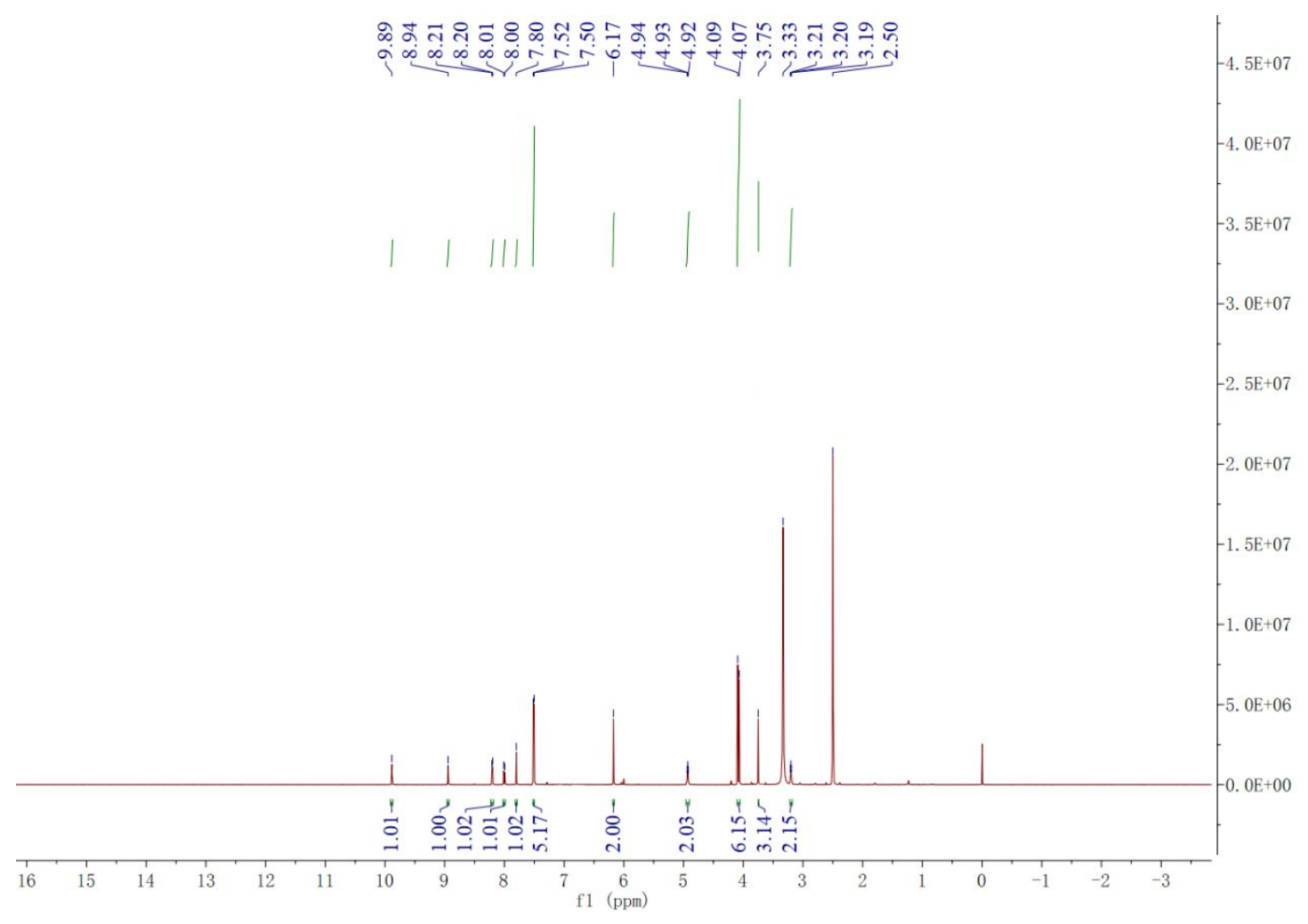

Figure S22 ${ }^{1} \mathrm{H}$ NMR Spectrum of Compound $\mathbf{8 1}$

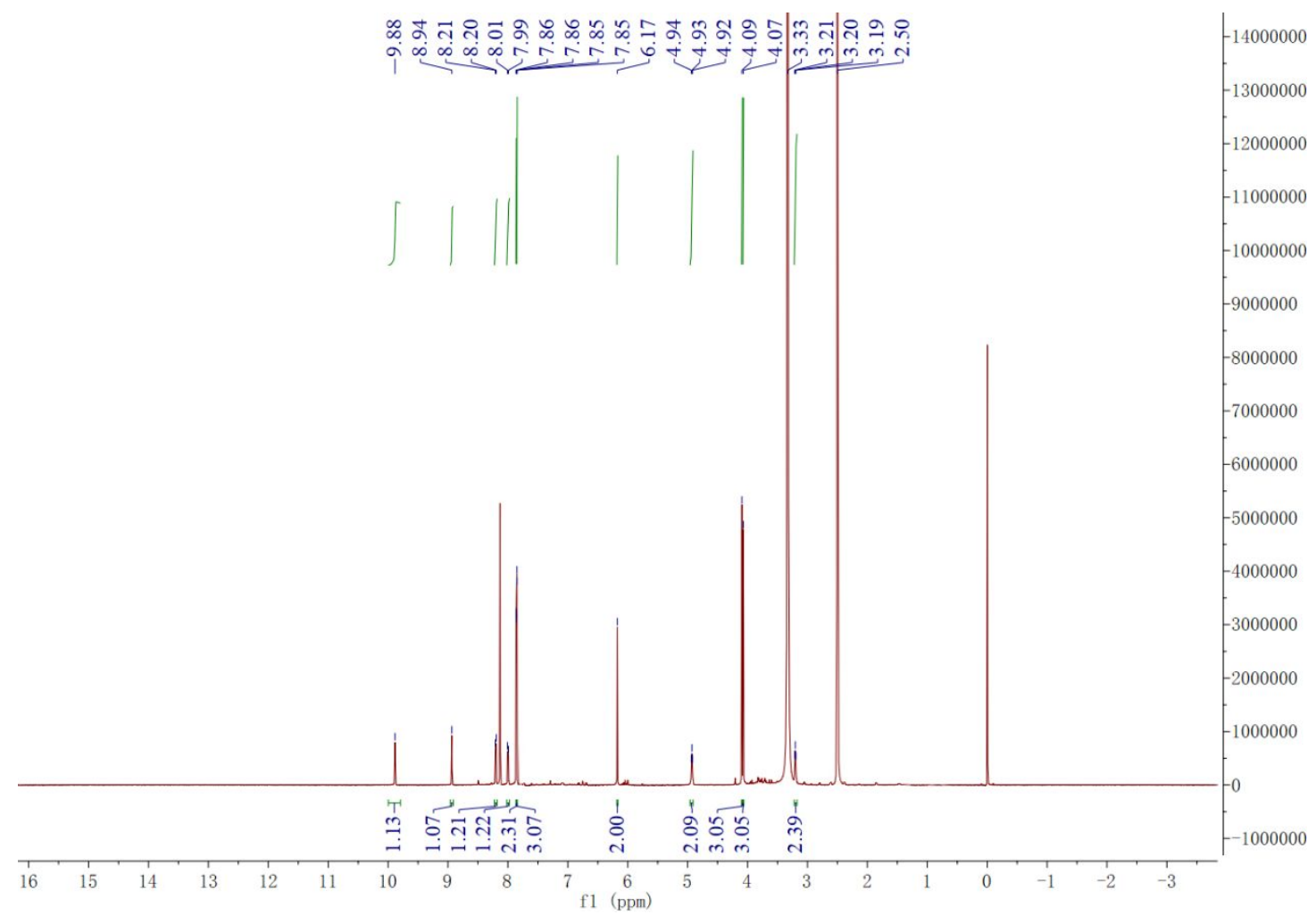


Figure S23 ${ }^{1} \mathrm{H}$ NMR Spectrum of Compound 7

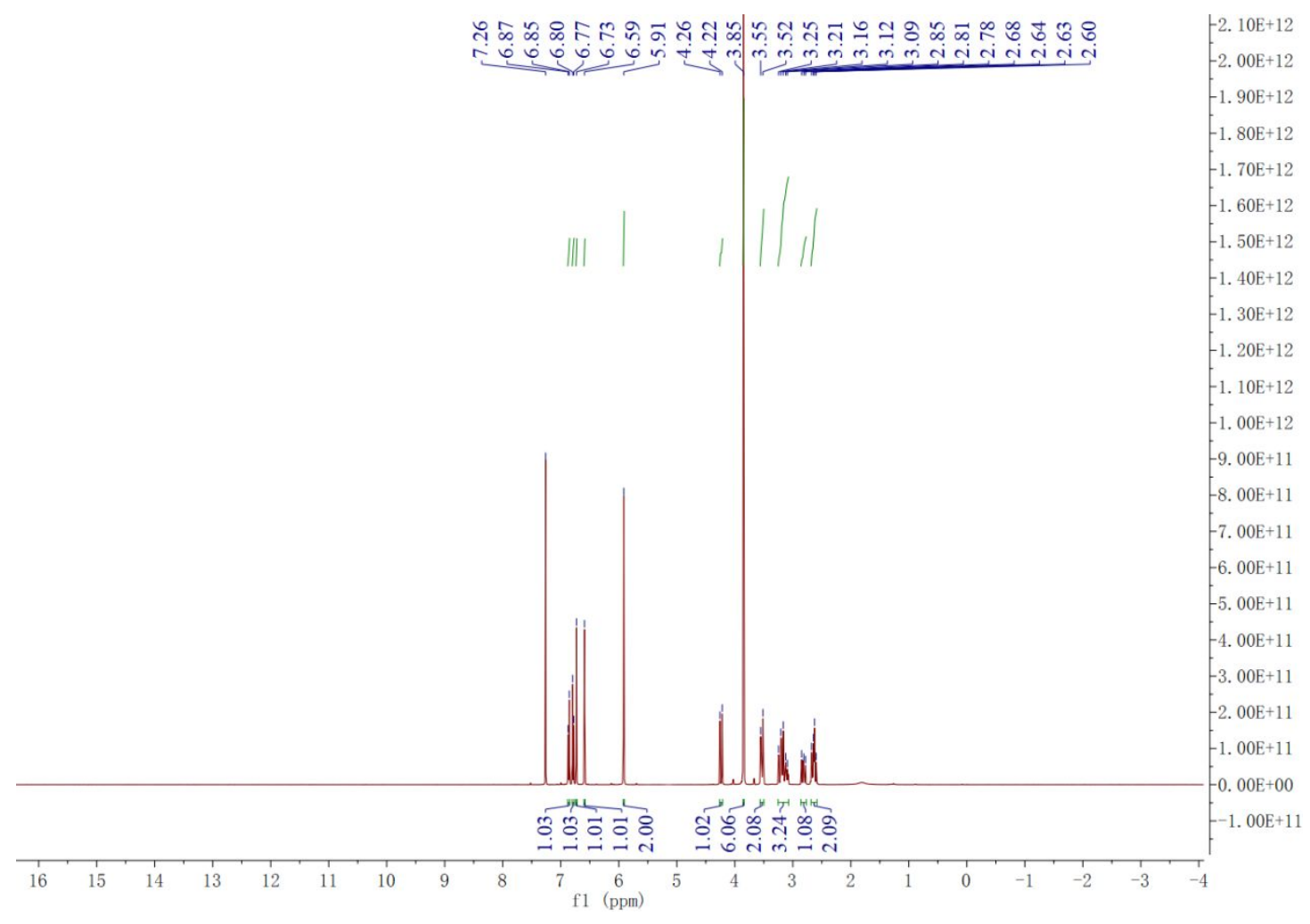

